\title{
Eating as Doing or Doing the Right Thing? The Influence of Locomotion and Assessment on Food Consumption Quantity
}

\author{
Tessa Dahlmans ${ }^{1}$, Frank Mathmann ${ }^{2}$ \\ ${ }^{1,2}$ Maastricht University, School of Business and Economics, Tongersestraat 53, 6211 LM Maastricht, the Netherlands
}

\section{ABSTRACT}

2016 Research Leap/Inovatus Services Ltd. All rights reserved.

DOI: $10.18775 / j i b r m .1849-8558.2015 .14 .3001$ URL: http://dx.doi.org/10.18775/jibrm.18498558.2015.14.3001

Keywords:

Overeating

Portion size

Regulatory mode theory

Food consumption quantities

\begin{abstract}
As overweight is becoming a serious worldwide health issue, a great amount of commercial books, programs and blogs are offering help in establishing healthy eating patterns. A factor that has commonly been blamed for overweight is the growth of portion sizes. This phenomenon of supersizing portions has created a distortion of portion sizes throughout the food industry and has been suggested to lead to overeating. The present study investigates the influence of locomotion and assessment orientations on food consumption quantities in conditions of distorted portion sizes. A survey was conducted in which participants $(\mathrm{N}=75)$ watched a short movie whilst being presented with a distorted food portion. The results of this study show that when controlling for an individual's level of hunger and movie engagement, locomotion decreases food consumption quantities. To conclude, it is suggested that when food portions are distorted locomotion assists in limiting an individual's food intake.
\end{abstract}

\section{Introduction}

The World Health Organization (WHO) indicated that around $39 \%$ of the global adult population was overweight in 2014. This presents a serious worldwide health issue as a high Body Mass Index (BMI) increases the risk of developing diabetes, some types of cancer and cardiovascular diseases (WHO, 2015). However, what has caused this worldwide epidemic of overweight? Research indicates that the fundamental cause of overweight and obesity is an imbalance between calories consumed and calories expended with increased energy intakes as a major contributing factor (Prentice \& Jebb, 2003; WHO, 2015). Particularly one factor that has commonly been known to increase energy intakes is portion size, as energy content increases with larger food quantities (Ledikwe, Ello-Martin, \& Rolls, 2005; Young \& Nestle, 2002).

As such, consuming an inappropriately large energy intake, also referred to as overeating, can contribute to the development of overweight (Prentice, 2001). However, it lies in our human nature to feel the desire to indulge while we actually know it is better not to, particularly when it concerns eating behaviour (Poelman, Vermeer, Vyth, \& Steenhuis, 2013). Thus, eating a super-sized bucket of ice cream or a large plate of creamy mac \& cheese is something that most of us are all too familiar with. It is such behaviour that fuels the food industry and forms our current eating environment characterized by relatively inexpensive, highly palatable and convenient foods served in large portions (Rolls, Morris, \& Roe, 2002). Mirroring these issues, a great amount of commercial books, blogs and programs are available that offer help in establishing a healthy eating pattern. This abundance in options reflects an apparent difficulty that people have with overcoming unhealthy eating behaviours such as eating too much. Furthermore, as people are confronted with increasingly larger food portions on a daily basis, we are challenged to maintain an energy intake appropriate to our needs (Ledikwe et al., 2005; Prentice \& Jebb, 2003; Young \& Nestle, 2002).

Research studies indicate that food portion sizes offered by restaurants, supermarkets and fast-food outlets have increased in size in Western society over the past decades, resulting in increased energy intakes (Diliberti, Bordi, Conklin, Roe, \& Rolls, 2004; Hill, Wyatt, Reed, \& Peters, 2003; Young \& Nestle, 2007). Other studies however state that we do not only risk overconsumption, but also by eating out as the size of dishware within our own homes has also increased over the years (Nielsen $\&$ Popkin, 2003). This phenomenon of supersizing portions is referred to as portion distortion and can influence consumer adaptation levels of how much we believe we should eat before we are satiated (Wansink \& Van Ittersum, 2007). Consequently, if portion sizes are distorted regardless of where the actual act of eating takes place, what exactly drives a person to eat a certain 
quantity of food? Previous research suggests that portion size serves as a normative cue which can affect all individuals, overweight or not, regarding their food intake. As people are rather uncertain as to how much they should eat in a given situation they rely on normative cues to provide guidance on consumption quantities (Herman \& Polivy, 2005; Herman \& Polivy, 2008). Therefore, when a portion or packet size is presented to an individual, it is considered to be an indicator of how much that individual should eat (Wansink \& Van Ittersum, 2007). Several studies indicate that regardless of the serving method at hand, a person's characteristics or demographics, larger food portion lead to greater energy intakes in both singlemeal settings and chronic exposure to larger portions (Jeffery et al., 2007; Rolls, Roe, Kral, Meengs, \& Wall, 2004; Rolls, Roe, \& Meengs, 2007). Consequently, larger portion sizes can cause overeating (Wansink \& Van Ittersum, 2007). Hence, portion size exerts a powerful influence on individuals who otherwise have no specific reason to start, continue or stop eating (Herman \& Polivy, 2008). The impact that such normative cues have in suggesting appropriate amounts to eat is grounded in the fact that individuals commonly do not have a clear sense of how saturated or hungry they are, except at levels of extremes (Herman \& Polivy, 2005).

Research also indicates that when a person was presented with a bigger portion of food that person ate a larger amount before satiation was reached, thus suggesting that portion size influences the development of satiety and hunger. Nevertheless, regardless of the amount of food presented to an individual, at a certain point that person will reach a maximum amount of food that he or she can consume (Rolls et al., 2002). Furthermore, other factors that have been known to influence people in consuming certain energy intakes are demographic variables, preferences, dislikes, physiological needs and psychological traits al (Eertmans, Victoir, Vansant, \& Van den Bergh, 2005). Specifically, gender has been suggested to have an affect on food choice and consumption, as women were found to attach greater importance to healthy eating and are more likely to be on a diet than men(Wardle et al., 2004). However, whilst previous research looked at the influence of demographic variables and other individual differences on food consumption, how these interact with portion size has received little attention.

Overall, the difficulty that some consumers face with eating appropriate quantities of food could be caused by the portion distortion throughout the food industry, which influences the amount of food people think they need to eat. Nevertheless, as some people do successfully manage to consume appropriate energy intakes the question remains as to what enables them to do so. A theory that could possibly explain the drive behind the overconsumption of food in conditions of distorted portion sizes is Regulatory Mode theory. However, due to scarce research on how individual differences influence food consumption, especially when portion size is taken into account, it is not possible to explain this possible link without empirical research. Therefore, the present research study will investigate the role of locomotion and assessment on the consumption of food quantities in conditions of distorted portion sizes.

\section{Regulatory Mode Theory - Locomotion and Assessment Affecting Food Consumption}

Regulatory Mode Theory describes two independent dimensions which entails a person's motivation to assess different goals and means to pursue those goals (assessment), as well as a motivation for initiating change or movement away from a current state to a different state (locomotion) (Kruglanski et al., 2000). Since locomotion and assessment have been found to predict behaviour in a wide variety of settings, it may be possible that these influence the consumption of food quantities as individuals can differ in regards to these tendencies (Higgins, Kruglanski, \& Pierro, 2003; Pierro, Giacomantonio, Pica, Kruglanski, \& Higgins, 2011; Pierro et al., 2008). Locomotion constitutes the part concerned with movement from state to state and commits psychological resources in order to initiate and maintain goalrelated movement in a direct manner without undue delays (Kruglanski et al., 2000). Hence, locomotion-orientated individuals are eager to get started on a certain task, put in effort to move on quickly to the next task and enjoy being in motion. For them, the greater the sensation of movement, the more intrinsically rewarded they feel (Avnet \& Higgins, 2003). Individuals who emphasize the locomotion orientation focus on "getting things done" and "getting on with it" (Kruglanski et al., 2000; Pierro et al., 2008). As such people have a motivational concern to initiate and maintain movement they are not likely to procrastinate, regardless of whether it concerns general habits or specific goals (Pierro et al., 2011). Conversely, assessment constitutes the comparative part concerned with critically evaluating states or entities (e.g. goals or means) in relation to alternatives in order to judge quality. Individuals who emphasize the assessment orientation relate both past and future actions to critical standards, and favour critical evaluations about themselves and others on various factors (Kruglanski et al., 2000; Pierro et al., 2008). Such individuals prefer to wait and thoroughly evaluate options before deciding on how to act (Avnet \& Higgins, 2003) and do so by choosing the option that has the best attributes in comparison to alternatives (Higgins et al., 2003). Additionally, individuals with a high assessment orientation are more likely to engage in counterfactual thinking and regret, which can lead to an increased sensitivity in making risky choices and postponing decisions (Pierro et al., 2008). Hence, an individual high on the assessment orientation aims to just do the "right thing" in a situation (Kruglanski et al., 2000).

By definition, it is suggested that locomotion and assessment can function as independent orientations and that one or the other can be emphasized by different people (Higgins et al., 2003; Kruglanski et al., 2000). Individuals can be high in on one orientation and low on the other, but also can be relatively high or relatively low in both functions. However, even for individuals who are high in both functions as an individual difference, one or the other regulatory mode may be triggered more heavily by a specific situation (Kruglanski et al., 2000). Specifically, situations can temporarily change individuals' regulatory mode 
orientations. For instance, some situations may naturally induce a stronger assessment mode, such as reading a book, whereas other situations may naturally induce a stronger locomotion mode, such as jogging. As regulatory modes can compete for a person's investment of resources (e.g. time, attention or energy), whichever mode is emphasized more heavily will be the predominant orientation influencing the nature and results of a specific goal pursuit (Higgins et al., 2003).

On the basis of these previous findings it is assumed that these regulatory orientations may also have an influence on eating behaviour, and more specifically food consumption quantities. For instance, research suggests that individuals with a strong locomotion orientation are driven to change their current state in a direct manner without undue delays towards goal pursuit (Kruglanski et al., 2000). Such individuals strive to initiate and maintain movement and are not likely to procrastinate once they have started with an activity(Pierro et al., 2011). As a result, it can be assumed that if one's goal would concern-eating individuals with a strong locomotion orientation will do so without undue delays in line with their motivational concern to initiate and maintain movement. As such, this process can be thought of as "eating as doing". Specifically, when presented with a distorted portion size this line of reasoning would suggest that locomotors care about progress even if they cannot completely finish the portion. Resultantly, locomotion is thought to have a positive effect on food consumption. Conversely, when engaging in an activity individuals with a strong assessment orientation strive to follow the most appropriate or correct course of action (Higgins et al., 2003). Thus, it is not uncommon for such individuals to disrupt a smooth task flow in order to evaluate the goal at hand during an activity (Kruglanski et al., 2000). This line of reasoning would suggest that assessors consume less food if the activity concerns eating according to their motivational concern to critically evaluate both the goal and means to reach it. In essence, this process can be thought of as "eating as to do the right thing". Specifically, when presented with a distorted portion size this line of reasoning would suggest that assessors would consciously not consume the entire portion as a result of critical evaluations. Resultantly, assessment is thought to have a negative effect on food consumption. Accordingly, the following central hypotheses concerning locomotion and assessment were formulated:

Hypothesis 1: Strong (vs. weak) locomotion has a positive effect on the consumption of food, thus increasing food consumption quantities

Hypothesis 2: Strong (vs. weak) assessment has a negative effect on the consumption of food, thus decreasing food consumption quantities

\section{Methods}

The collection of data was performed through conducting a survey whilst presenting participants with a distorted portion size for a specific amount of time. The research sample consisted of 75 subjects $(\mathrm{N}=75)$, of which 42 were female and the majority of the subjects originated from Germany (54.7\%) and the Netherlands (26.7\%). For the first part of the survey participantswere asked to watch a shortvideo during which they each were presented with a bowl of chocolate peanuts (i.e., 250 grams).Once the video was finished, the survey instructed participants to raise their hands after which the chocolate peanuts were removed from their sight by the observant and the second part of the experiment started. Participants were then asked to fill out a series of questions regarding their level of movie engagement, locomotion and assessment tendencies, eating behaviour and concerns, and demographics. Once all participants had completed the survey and left the room, the bowls with the remaining quantities of chocolate peanuts were weighed by use of a food weighing scale.

\section{Results}

The hypotheses were tested through means of a multiple regression in which locomotion $(\alpha>.87)$ and assessment $(\alpha>$ .70) served as independent variables and eating behaviour (food eaten in grams) as the dependent variable. Further, both 'hunger level before experiment' and movie engagement through 'pleasure' and 'arousal' were controlled for. The regression analysis revealed that locomotion has a statistically significant negative effect on food consumption quantities $(\beta=-.261 ; p$ $<.01)$. In addition, the control variable 'hunger level before experiment' proved to have a significant positive effect $(\beta=.550$; $\mathrm{p}<.001$ ) and 'movie engagement arousal' a significant negative effect of food consumption quantities $(\beta=-.255 ; \mathrm{p}<.05)$. Together with assessment and 'movie engagement pleasure' these variables explained for $42.2 \%$ of the variance in eating behaviour. Thus, the results indicate that when controlling for hunger levels and movie engagement, locomotion has a significant negative effect on eating behaviour whilst assessment has no effect on eating behaviour. Hence, on the basis of these results it seems justifiable to conclude that both $\mathrm{H} 1$ and $\mathrm{H} 2$ were not supported. Furthermore, the results indicate that whilst 'movie engagement pleasure' does not have an effect on eating behaviour, 'movie engagement arousal' does have a significant negative effect on eating behaviour.

\section{General Discussion and Conclusions}

The results presented in this research study provide important insights into consumer behaviour, and more specifically food consumption. The results of this study indicate that when controlling for hunger levels and movie arousal locomotion has a significant negative effect on eating behaviour, thus decreasing food consumption quantities. Also, assessment was found to have no significant effect on eating behaviour. Although previous research suggests that increasingly larger portions have been found to cause overeating in a wide variety of settings (Jeffery et al., 2007; Rolls et al., 2004; Rolls et al., 2007), the current study possibly suggests otherwise. Hence, as portion sizes have increased in size over the past decades is the act of finishing one's plate still feasible? Or have plates simply become too large to finish? The negative effect of locomotion on food consumption quantities could possibly be explained by regulatory fit theory. This theory suggests that when an individual experiences regulatory fit motivational strength is enhanced, which improves efforts at attaining a goal and results in an "it- 
just-feels-right" experience (Aaker \& Lee, 2006; Avnet \& Higgins, 2003; Higgins, 2000). One could argue that individuals with a strong locomotion orientation experience eating a distorted portion size as a "non-fit" experience, since it does not sustain their regulatory orientation. Accordingly, as individuals with a strong locomotion orientation care about performing an activity and persisting until completion (Kruglanski, Orehek, Higgins, Pierro, \& Shalev, 2009), attempting to finish a portion in its entirety could result in a perceived negative experience (Avnet \& Higgins, 2003). Based on the results of this study, one could argue that when food portions are distorted or unlimited locomotion might actually assist limiting an individual's food intake. Contrarily, following this line of reasoning it would be expected that individuals with a weak locomotion orientation might not contain themselves when such distorted portions are presented to them. This might especially be the case in regards to 'all-you-can-eat' restaurants, where portion sizes are in essence limitless. In the present study each participant was presented with a distorted portion of chocolate peanuts (i.e. 250 grams). In line with the assumption, none of the participants in the study were able to finish the distorted portion presented to them. Consequently, it is believed that locomotion might have limited the intake of this distorted portion of food leading to the results as presented earlier. Furthermore, as locomotion and assessment form independent psychological orientations, the possibility exists that eating behaviour constitutes a specific domain to which only locomotion pertains and assessment does not (Kruglanski, Pierro, Mannetti, \& Higgins, 2013).

Finally, the limitations concerning the present study are two-fold. Firstly, the current study focuses only on eating behaviour, measured by chocolate peanuts eaten in grams at a specific moment in time, as an outcome variable. Therefore, the findings do not permit drawing conclusions on eating behaviour when they occur in an individual's natural environment or when it occurs in the presence of others. Secondly, as no control group was applied to test different conditions regarding eating behaviour (e.g., watching a video vs. listening to music while eating)the results are rather limited to the setting of the present study. Furthermore, it is suggested that future research could focus on the effects of locomotion on eating behaviour when participants are presented with different portion sizes.

\section{References}

- Aaker, J. L., \& Lee, A. Y. (2006). Understanding regulatory fit. Journal of Marketing Research, 43(1), 15-19, CrossRef

- Avnet, T., \& Higgins, E. T. (2003). Locomotion, assessment, and regulatory fit: Value transfer from "how" to "what". Journal of Experimental Social Psychology, 39(5), 525-530, CrossRef

- Diliberti, N., Bordi, P. L., Conklin, M. T., Roe, L. S., \& Rolls, B. J. (2004). Increased portion size leads to increased energy intake in a restaurant meal. Obesity research, 12(3), 562-568, CrossRef

- Eertmans, A., Victoir, A., Vansant, G., \& Van den Bergh, O. (2005). Food-related personality traits, food choice motives and food intake: Mediator and moderator relationships. Food Quality and Preference, 16(8), 714-726, CrossRef

- Herman, P., \& Polivy, J. (2005). Normative influences on food intake. Physiology \& behavior, 86(5), 762-772, CrossRef

- Herman, P., \& Polivy, J. (2008). External cues in the control of food intake in humans: the sensory-normative distinction. Physiology \& Behavior, 94(5), 722-728, CrossRef

- Higgins, E. T. (2000). Making a good decision: value from fit. American psychologist, 55(11), 1217, CrossRef

- $\quad$ Higgins, E. T., Kruglanski, A. W., \& Pierro, A. (2003). Regulatory Mode: Locomotion and Assessment as Distinct Orientations.

- Hill, J. O., Wyatt, H. R., Reed, G. W., \& Peters, J. C. (2003). Obesity and the environment: where do we go from here? Science, 299(5608), 853-855, CrossRef

- Jeffery, R. W., Rydell, S., Dunn, C. L., Harnack, L. J., Levine, A. S., Pentel, P. R., . . . Walsh, E. M. (2007). Effects of portion size on chronic energy intake. International Journal of Behavioral Nutrition and Physical Activity, 4(1), 27, CrossRef

- Kruglanski, A. W., Orehek, E., Higgins, E. T., Pierro, A., \& Shalev, I. (2009). Assessment and Locomotion as Independent Determinants in Goal Pursuit. Handbook of personality and self-regulation, 375 .

- Kruglanski, A. W., Pierro, A., Mannetti, L., \& Higgins, T. E. (2013). The distinct psychologies of "looking" and "leaping": Assessment and locomotion as the springs of action. Social and Personality Psychology Compass, 7(2), 79-92, CrossRef

- Kruglanski, A. W., Thompson, E. P., Higgins, E. T., Atash, M., Pierro, A., Shah, J. Y., \& Spiegel, S. (2000). To" do the right thing" or to" just do it": locomotion and assessment as distinct self-regulatory imperatives. Journal of personality and social psychology, 79(5), 793, CrossRef

- $\quad$ Ledikwe, J. H., Ello-Martin, J. A., \& Rolls, B. J. (2005). Portion sizes and the obesity epidemic. The Journal of nutrition, 135(4), 905-909.

- Nielsen, S. J., \& Popkin, B. M. (2003). Patterns and trends in food portion sizes, 1977-1998. Jama, 289(4), 450-453, CrossRef

- $\quad$ Pierro, A., Giacomantonio, M., Pica, G., Kruglanski, A. W., \& Higgins, E. T. (2011). On the psychology of time in action: regulatory mode orientations and procrastination. Journal of personality and social psychology, 101(6), 1317, CrossRef

- Pierro, A., Leder, S., Mannetti, L., Tory Higgins, E., Kruglanski, A. W., \& Aiello, A. (2008). Regulatory mode effects on counterfactual thinking and regret. Journal of Experimental Social Psychology, 44(2), 321329, CrossRef

- Poelman, M. P., Vermeer, W. M., Vyth, E. L., \& Steenhuis, I. H. (2013). 'I don't have to go to the gym 
because I ate very healthy today': the development of a scale to assess diet-related compensatory health beliefs. Public health nutrition, 16(02), 267-273, CrossRef

- Prentice, A. M. (2001). Overeating: the health risks. Obesity research, 9(S11), 234S-238S, CrossRef

- Prentice, A. M., \& Jebb, S. A. (2003). Fast foods, energy density and obesity: a possible mechanistic link. Obesity reviews, 4(4), 187-194, CrossRef

- $\quad$ Rolls, B. J., Morris, E. L., \& Roe, L. S. (2002). Portion size of food affects energy intake in normal-weight and overweight men and women. The American journal of clinical nutrition, 76(6), 1207-1213.

- $\quad$ Rolls, B. J., Roe, L. S., Kral, T. V., Meengs, J. S., \& Wall, D. E. (2004). Increasing the portion size of a packaged snack increases energy intake in men and women. Appetite, 42(1), 63-69, CrossRef

- Rolls, B. J., Roe, L. S., \& Meengs, J. S. (2007). The effect of large portion sizes on energy intake is sustained for 11 days. Obesity, 15(6), 1535-1543, CrossRef

- Wansink, B., \& Van Ittersum, K. (2007). Portion size me: downsizing our consumption norms. Journal of the American Dietetic Association, 107(7), 1103-1106, CrossRef

- Wardle, J., Haase, A. M., Steptoe, A., Nillapun, M., Jonwutiwes, K., \& Bellisie, F. (2004). Gender differences in food choice: the contribution of health beliefs and dieting. Annals of Behavioral Medicine, 27(2), 107-116, CrossRef

- WHO. (2015). Obesity and Overweight. Factsheet, from http://www.who.int/mediacentre/factsheets/fs311/en/

- Young, L. R., \& Nestle, M. (2002). The contribution of expanding portion sizes to the US obesity epidemic. American journal of public health, 92(2), 246-249, CrossRef

- Young, L. R., \& Nestle, M. (2007). Portion sizes and obesity: responses of fast-food companies. Journal of public health policy, 28(2), 238-248, CrossRef 